\title{
Germ-line passage is required for establishment of methylation and expression patterns of imprinted but not of nonimprinted genes
}

\author{
Kerry Lee Tucker, ${ }^{1,2}$ Caroline Beard, ${ }^{1}$ Jessica Dausman, ${ }^{1}$ Laurie Jackson-Grusby, ${ }^{1}$ Peter W. Laird, ${ }^{1,4}$ \\ Hong Lei, ${ }^{3} \mathrm{En} \mathrm{Li}^{3}$ and Rudolf Jaenisch ${ }^{1,2,5}$ \\ ${ }^{1}$ Whitehead Institute for Biomedical Research, ${ }^{2}$ Massachusetts Institute of Technology, Department of Biology, Cambridge, \\ Massachusetts 02142 USA; ${ }^{3}$ Massachusetts General Hospital East, Cardiovascular Research Center, Charlestown, \\ Massachusetts 02129 USA
}

Embryonic stem (ES) cells homozygous for a disruption of the DNA (cytosine-5)-methyltransferase gene (Dnmt) proliferate normally with their DNA highly demethylated but die upon differentiation. Expression of the wild-type Dnmt cDNA in mutant male ES cells caused an increase in methylation of bulk DNA and of the Xist and Igf2 genes to normal levels, but did not restore the methylation of the imprinted genes $\mathrm{H} 19$ and Igf2r. These cells differentiated normally in vitro and contributed substantially to adult chimeras. While the Xist gene was not expressed in the remethylated male ES cells, no restoration of the normal expression profile was seen for $H 19$, Igf $2 r$, or $I g f 2$. This indicates that ES cells can faithfully reestablish normal methylation and expression patterns of nonimprinted genes but lack the ability to restore those of imprinted genes. Full restoration of monoallelic methylation and expression was imposed on $\mathrm{H19}$, Igf2, and Igf2r upon germ-line transmission. These results are consistent with the presence of distinct de novo DNA methyltransferase activities during oogenesis and spermatogenesis, which specifically recognize imprinted genes but are absent in the postimplantation embryo and in ES cells.

[Key Words: DNA methylation; genomic imprinting; DNA methyltransferase; Igf2; H19; Igf2r; Xist]

Received January 16, 1996; revised version accepted March 1, 1996.

Much evidence indicates that in vertebrates the methylation of DNA at cytosine residues correlates with gene inactivity (Yeivin and Razin 1993). Methylation patterns are generally stably maintained in somatic cells of the animal but change dramatically during early development when the genome of the mammalian embryo undergoes consecutive waves of demethylation and de novo methylation (Razin and Shemer 1995). The methylation present in the DNA of the zygote is erased during cleavage so that the genome of the blastocyst is almost completely unmethylated (Monk et al. 1987; Kafri et al. 1992). After implantation, the embryo undergoes a wave of global de novo methylation that restores the genomic methylation levels of the gastrulating embryo to that seen in the adult (Jähner et al. 1982; Monk et al. 1987). During gametogenesis, the unmethylated DNA of the primordial germ cells becomes de novo methylated (Monk et al. 1987; Kafri et al. 1992), a process that ultimately leads to the high methylation levels of the zy-

${ }^{4}$ Present address: Norris Comprehensive Cancer Center, Los Angeles, CA 90033 USA.

${ }^{5}$ Corresponding author. gote. De novo methylation of transduced retroviral genomes is also seen in pregastrulation embryos (Jähner et al. 1982) and in embryonic carcinoma (EC) and stem (ES) cells (Stewart et al. 1982; H. Lei, S.P. Oh, R. Jüttermann, R. Jaenisch, K.A. Goss, and E. Li, in prep.), consistent with the hypothesis that a de novo DNA methyltransferase activity is expressed in early stages of development.

The crucial importance of DNA methylation in development was demonstrated by the targeted mutation of the single known mammalian DNA methyltransferase gene (Dnmt) in ES cells (Li et al. 1992). Dnmt is believed to encode a maintenance methyltransferase, because in vitro the enzyme (MTase) shows a substrate preference for hemimethylated DNA (Gruenbaum et al. 1982; Bestor and Ingram 1983). Three mutant alleles of the Dnmt gene have been generated (Li et al. 1992, 1993; H. Lei, S.P. Oh, R. Jüttermann, R. Jaenisch, K.A. Goss, and E. Li, in prep.). A partially inactivated allele $\left(D n m t^{n}\right)$ causes lethality of homozygous mutant embryos at the 25 somite stage, whereas embryos homozygous for completely inactivated alleles $\left(D n m t^{s}\right.$ and $\left.D n m t^{c}\right)$ die at the 5 somite stage. ES cells homozygous for any of the alleles 
proliferate normally with their genomic DNA highly demethylated but die upon induction of differentiation. ES cells homozygous for any disruption, however, retain the ability to de novo methylate transduced DNA, supporting the notion of an independently encoded de novo DNA methyltransferase being expressed in embryonic cells (H. Lei, S.P. Oh, R. Jütterman, R. Jaenisch, K.A. Goss, and $\mathrm{E}$. Li, in prep.).

Imprinted genes display parent-specific monoallelic expression (Surani 1994; Barlow 1995), although often not at all developmental stages (Szabo and Mann 1995). Genes that are predominantly expressed from the maternal allele include Igf2r (Barlow et al. 1991), H19 (Bartolomei et al. 1991), Mash2 (Guillemot et al. 1995) and p57 ${ }^{K I P 2}$ (Hatada and Mukai 1995), whereas Igf2 (DeChiara et al. 1991), Mas (Villar and Pedersen 1994), Snrpn (Leff et al. 1992), U2afbp-rs (Hayashizaki et al. 1994), ins1/ins2 (Giddings et al. 1994), IPW (Wevrick et al. 1994), and Peg1/Mest (Kaneko-Ishino et al. 1995) are expressed paternally. DNA methylation has been proposed to constitute the molecular mark that distinguishes the two alleles of imprinted genes. Evidence for DNA methylation constituting the imprinting mark includes differential methylation of imprinted transgenes (Reik et al. 1987; Sapienza et al. 1987; Swain et al. 1987; Chaillet et al. 1991) and imprinted endogenous genes. The acquisition and developmental propagation of the methylation mark has been described in detail for the two imprinted genes $H 19$ and $I g f 2 r$, and for Xist, a gene encoded at the center for $\mathrm{X}$ chromosome inactivation that shows imprinted expression only in preimplantation embryos and extraembryonic tissues (Kay et al. 1993). The H19 gene acquires paternal-specific methylation in a region upstream of its promoter during spermatogenesis (Tremblay et al. 1995), whereas Igf2r (Stöger et al. 1993) and Xist (Ariel et al. 1995; Zuccotti and Monk 1995) acquire a maternal-specific methylation mark during oogenesis. Importantly, the allele-specific methylation differences in these "imprinting boxes" are resistant to the wave of global demethylation during cleavage and the subsequent wave of global de novo methylation before gastrulation (Bartolomei et al. 1993; Brandeis et al. 1993; Stöger et al. 1993; Tremblay et al. 1995). This assures that the methylation mark imposed on the two alleles of imprinted genes during gametogenesis remains unaltered during development and, therefore, distinguishes the two alleles in each cell of the organism. In contrast to $H 19$ and Igf2r, the methylation imprint of the maternal Xist allele is erased after implantation in cells of the embryonic lineage, and either the paternal or the maternal allele becomes methylated at the time of $\mathrm{X}$ inactivation (Norris et al. 1994).

Strong evidence for methylation being crucial for the maintenance of monoallelic expression of imprinted genes was provided by the analysis of Dnmt mutant embryos (Li et al. 1993; Beard et al. 1995). Hypomethylation of the DNA in mutant embryos or ES cells resulted in loss of monoallelic expression, either in the activation of the inactive $\mathrm{H} 19$ and Xist alleles or in the inactivation of the active $I g f 2 r$ and $I g f 2$ alleles. These experiments did not, however, provide insights into the role of methylation in the establishment of genomic imprinting during gametogenesis.

In this paper we address the process by which the allele-specific methylation of imprinted genes is acquired. We have expressed the wild-type Dnmt cDNA in homozygous Dnmt mutant ES cells to assess whether this would restore the low methylation levels of the genomic DNA to normal. Although normal methylation levels of nonimprinted DNA were reestablished, imprinted genes were neither remethylated nor appropriately expressed. However, passage of the remethylated ES cells through the germ line restored normal methylation and expression to all imprinted genes analyzed.

\section{Results}

Expression of functional MTase in Dnmt mutant ES cells leads to restoration of genomic methylation

Previous work had demonstrated that the DNA of homozygous mutant Dnmt ES cells was highly hypomethylated ( $\mathrm{Li}$ et al. 1992; H. Lei, S.P. Oh, R. Jüttermann, R. Jaenisch, K.A. Goss, and E. Li, in prep.). To assess whether expression of the wild type MTase would restore genomic methylation levels and rescue the lethal phenotype of differentiated mutant cells, we introduced the Dnmt cDNA into mutant ES and embryonic germ (EG) cells. The two cell types displayed identical molecular characteristics and functional capacity before and after expression of the Dnmt cDNA. For the sake of simplicity, they are collectively referred to as ES cells in the text. To assure correct quantitative and developmental expression of the construct, the cDNA was inserted by homologous recombination into the cognate Dnmt locus upstream of the mutation, using a strategy we refer to as CHIP ( $\underline{c} D N A$ homologous insertion protocol; see Materials and methods). The vector (Fig. 1A) fused the Dnmt cDNA $3^{\prime}$ to a $4.8-\mathrm{kb}$ piece of genomic Dnmt sequence that ended in the second known exon (Rouleau et al. 1992). Homologous insertion of this hybrid vector was expected to leave all upstream control elements of the gene intact, leading to restoration of normally regulated MTase expression. Dnmt mutant cells were electroporated with the linearized construct and selected for puromycin resistance. All puromycin-resistant colonies were expanded and analyzed by Southern blot analysis for vector integration and levels of genomic methylation. Genomic DNA was digested with ScaI and Southern blots were hybridized with probe HV. This yielded a $17.5-\mathrm{kb}$ fragment in wild-type $\mathrm{Jl}$ and Dnmt mutant cell lines (Fig. 1B, lanes 1,2), but a 22- and a 7.4-kb fragment for the targeted allele of an homologous integrant (lanes 3,4). By this analysis, 73 of 182 puromycin-resistant clones had undergone homologous recombination events in which a single copy of the plasmid integrated at a single allele (data not shown). Northern blot analysis was used to assess the level of Dnmt transcription. The size of the endogenous mRNA is $5.2 \mathrm{~kb}$ (Fig. 1C, lane 1). Virtually no mRNA of this size was observed in homozygous mu- 
Figure 1. Targeting of the Dnmt cDNA to its cognate locus results in normal expression levels of Dnmt mRNA. (A) Diagram representing the Dnmt-targeting construct pMWT-PURO and its method of integration into the Dnmt locus. pMWT-PURO is represented schematically. A 4.8-kb Dnmt genomic sequence that is shared between pMWT-PURO and the Dnmt locus is indicated by a broken line and two dark boxes corresponding to the first two exons, drawn to scale. This was fused to the remainder of the Dnmt cDNA (hatched box) in the second exon at a NaeI (N) site, 20 bp upstream of the initial ATG. A Pgk-1-derived polyadenylation sequence (Pgk-PolyA) was inserted at the end of the CDNA, and the plasmid also contained a puromycin-selectable marker (Pgk-Puro) and pGEM-11zf $\mid+$ | bacterial plasmid sequences $\left(A_{m} p^{Y}\right)$. The HindIII linearization site is indicated $(\mathrm{H})$. The Dnmt locus targeted with this construct is represented beneath by a broken line upstream of the same two exons depicted in pMWT-PURO. The genomic probe $(\mathrm{HV})$ for Southern blot analysis and the ScaI (S) digestion product expected from the locus are also displayed. HindIII $(\mathrm{H})$ and NaeI (N) sites are as indicated above. Within the vertical arrow is a closeup, drawn to scale, of the crossover event in which pMWT-PURO was targeted to the Dnmt locus. The plasmid was cut at the unique HindIII $(\mathrm{H})$ site indicated, and after electroporation the entire vector homologously inserted into the endogenous gene, yielding the genomic structure shown beneath. pMWT-PURO shares 4.1 and $0.7 \mathrm{~kb}$ of sequence identity with the target locus $5^{\prime}$ and $3^{\prime}$, respectively, of the HindIII linearization site. The bottom schematic illustrates the duplication of the $4.8-\mathrm{kb}$ Dnmt genomic sequence expected upon integration, seen with the exons (dark boxes) drawn to scale. It also displays the two products expected from a ScaI (S) digestion, using the HV probe. The scale is interrupted by several breaks in the genomic sequence, indicated by slashes through the line. The integrated pMWT-PURO plasmid is indicated by a solid line. $(B)$ Southern blot analysis of Dnmt-targeted clones. ScaI-digested genomic DNA displayed a single 17.5-kb band from both untargeted Dnmt alleles in wild-type $J 1$ (lane 1 ) and homozygous Dnmt mutant (lane 2) cells. Homologous insertion of a single copy of the pMWT-PURO plasmid at the Dnmt locus resulted in production of 21-and 7.4-kb bands $($ lanes 3,4$)$. The untargeted allele is also visible at $17.5 \mathrm{~kb}$. HindIII-digested $\lambda$ DNA size standards are indicated to the left. $|C|$ Northern blot analysis of Dnmt expression in ES cell lines stably transfected with pMWT-PURO. Total RNA was prepared from the homologous integrants shown in $B$ (lanes 4,5), and the Dnmt cDNA was used as a probe for the Northern blot (top). The following cells are shown for comparison: wild-type J1 (lane 1), a heterozygous (lane 21, and homozygous (lane 31 Dnmt mutant cell line. (Bottom) The same blot rehybridized with an $\alpha$-tubulin cDNA, to control for amount of RNA loaded. The positions of the $28 \mathrm{~S}$ and $18 \mathrm{~S}$ rRNA species are indicated at left.

tant Dnmt cells (lane 3). Puromycin-resistant cells that underwent homologous recombination (lanes 4,5) showed that the inserted cDNA was transcribed at a level and size comparable to that of the endogenous allele (lane 2).

All 73 homologous recombinants examined showed near-complete genomic remethylation (Fig. 2), as assayed using two repetitive sequence probes: a Moloney murine leukemia virus (MoMuLV) cDNA, which cross-hybridizes with endogenous C-type retroviruses scattered throughout the genome (Stuhlmann et al. 1981), and a minor satellite centromeric repeat /Chapman et al. 19841. Both of these repeated sequences are heavily methylated in 11 cells (Fig. 2, lane 1), as seen by Southern blot analysis of genomic DNA digested with HpaII, an enzyme sensitive to the methylation of internal cytosines in its CCGG recognition sequence. DNA methylation in Dnmt mutant cells was highly reduced (lane 2 ), as seen by the increasing intensity of lower molecular weight bands in Dnmt mutant cell lines. The methylation level of both sequences was restored to normal in all clones with a homologously integrated construct 

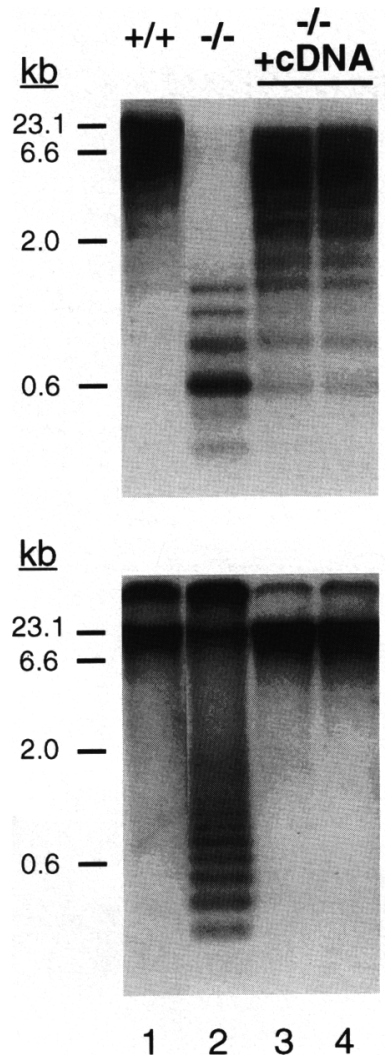

Figure 2. Normal genomic DNA methylation levels are restored upon expression of the Dnmt cDNA. Southern blot analysis of HpaII-digested genomic DNA, probed with either of two repetitive sequences: MoMuLV cDNA $\mid$ top $\mid$ or a centromeric minor satellite repeat (bottom). Wild-type Il (lane 1 ) and homozygous Dnmt mutant ES cells (lane 2) are shown, followed by the rescued mutant cells seen in Fig. 1 (lanes 3,4). HindIII-digested $\lambda$ DNA size standards are indicated to the left of each blot.

(lanes 3,4). No puromycin-resistant clones in which pMWT-PURO had integrated nonhomologously displayed either Dnmt expression or genomic remethylation (data not shown). We conclude that remethylation of bulk DNA in the genome of homozygous mutant Dnmt cells is achieved by expression of the Dnmt cDNA from its endogenous promoter. Dnmt mutant cells that express the cDNA shall henceforth be referred to as "rescued" cells.

\section{MTase expression complements lethal phenotype of differentiating mutant Dnmt ES cells}

Previous observations indicated that homozygous mutant Dnmt ES cells, although proliferating normally when undifferentiated, die upon induction of differentiation (Beard et al. 1995; H. Lei, S.P. Oh, R. Jüttermann, R. Jaenisch, K.A. Goss, and E. Li, in prep.) and do not contribute to adult chimeras after injection into wildtype blastocysts (see below). We were interested to test whether restoration of genomic DNA methylation levels in mutant ES cells carrying the Dnmt cDNA would rescue the lethal mutant phenotype. To test in vitro differentiation, the rescued cells were induced to differentiate by plating on bacteriological petri dishes, in the absence of a fibroblast feeder layer and leukemia inhibitory factor (LIF). In contrast to the parental mutant cells (H. Lei, S.P. Oh, R. Jüttermann, R. Jaenisch, K.A. Goss, and E. Li, in prep.l, the rescued cells differentiated and proliferated normally (data not shown). This indicates that in vitro differentiation potential was restored by genomic remethylation.

To test the developmental potential of the remethylated cells more stringently, in vivo experiments were conducted. First, the cells were injected subcutaneously into syngeneic male host animals. Although the parental mutant cells failed to form palpable teratomas within 3-4 weeks $(n=0 / 24)$, the rescued ES cells induced teratoma formation at a similar rate $(n=21 / 24)$ as the wildtype J1 ES cells $(n=11 / 12)$. Second, the rescued cells were injected into wild-type BALB/c blastocysts to test their ability to contribute to chimeras. The parental Dnmt mutant cells were completely incapable of contributing to adult chimeras $(n=0 / 64$ injected blastocysts). When rescued cells were used instead, 11 chimeras were generated with donation to coat color ranging from $10 \%$ to $70 \%(n=11 / 92$ injected blastocysts). The animals appeared normal in size and appearance, and contribution to the germ line was observed in three chimeras derived from two rescued cell lines (see below).

The results described so far show that expression of functional MTase in Dnmt mutant ES cells restores normal methylation levels and results in the rescue of the lethal mutant phenotype.

\section{Methylation and monoallelic expression of imprinted genes are not restored in rescued ES cells}

The methylation levels and expression of the imprinted genes H19, Igf2r, Igf2, and Xist were assessed by Southern blot and by RNase protection analysis. The analyses were performed on undifferentiated and in vitro-differentiated ES cells. To investigate methylation and expression in terminally differentiated cells, fibroblasts were isolated from the chimeras described above. Primary fibroblast cultures were prepared from the carcasses of four chimeras. The primary cultures were immortalized with SV40 virus and then selected with puromycin to enrich for cells derived from the injected ES cells. Puromycin-selected populations were then subcloned at limiting dilution to prevent contamination from wild-type fibroblasts.

Methylation of H19 In normal ES cells and mice a 3.8$\mathrm{kb}$ region just upstream of the promoter displays a monoallelic methylation pattern (Bartolomei et al. 19931, in which the paternally derived allele is completely methylated (migrating at $3.8 \mathrm{~kb}$, Fig. 3A, lanes 
Tucker et al.

A

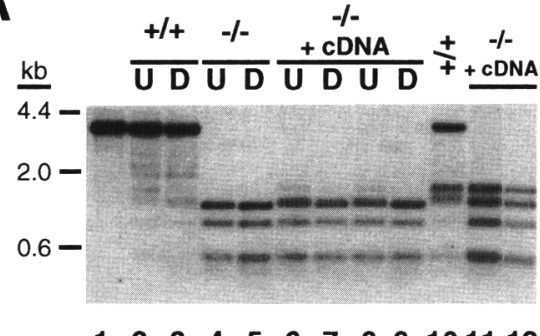

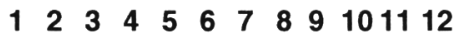

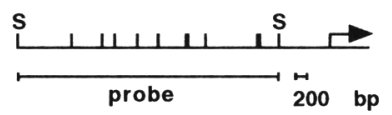

B

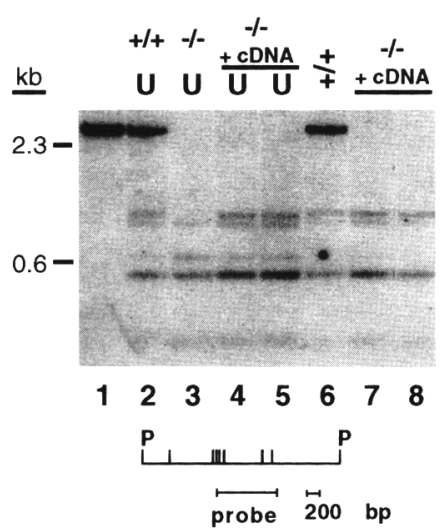

C

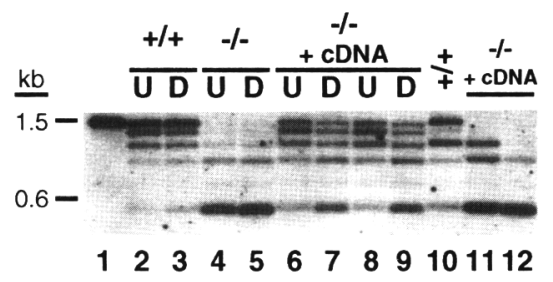

Igf2

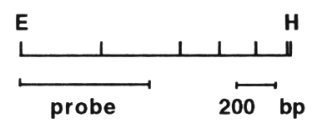

D

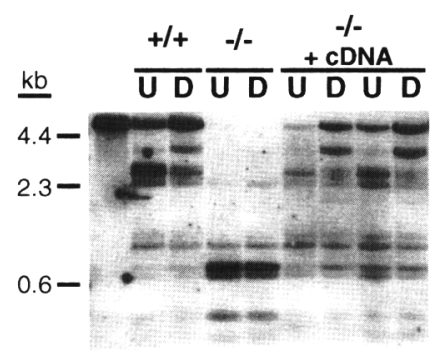

$\begin{array}{lllllllll}1 & 2 & 3 & 4 & 5 & 6 & 7 & 8 & 9\end{array}$

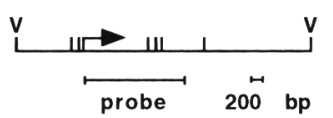

Figure 3. Methylation of the imprinted genes $H 19$ and $I g f 2 r$ is not restored in rescued ES cells and their differentiated derivatives, but methylation of Xist and Igf2 is restored to normal. Southern blot analysis of ES cells and fibroblast cultures derived from postnatal chimeras made with rescued ES cells. $(A-D)$ Genomic DNA was isolated from undifferentiated (U) or differentiated (D) ES cells, cut with SacI, PvuII, EcoRI-HindIII, or EcoRV $\mid A, B, C$, and $D$, lanes 1, respectively $\mid$, and probed with the gene sequence indicated beneath each respective blot. All other lanes were treated similarly but include the methylation-sensitive enzymes $H h a \mathrm{I}(A, D)$ or $H p a I I(B, C)$. Wild-type $\mathrm{Il}(+1+1$, homozygous Dnmt mutant $(-1-1$, and two independent rescued cell lines $(-/-+\operatorname{cDNA})$ are shown. $(A$ and $C$, lanes $10-12 ; B$, lanes $6-8 \mid$ SV40 virus-immortalized fibroblast cultures were examined. Fibroblasts were derived from an embryonic day 16.5 wild-type embryo $(A$ and $C$, lanes $10 ; B$, lane 6$)$ and were compared with puromycin-resistant fibroblasts derived from two postnatal chimeras $(A$ and $C$, lanes 11 and $12 ; B$, lanes 7 and 8$)$. The puromycin-resistant cells were shown to be derived exclusively from the injected rescued ES cells (data not shown). A map of the examined area is shown beneath each blot, with flanking SacI (S), PvuII (P), EcoRI (E), HindIII (H), and EcoRV $(\mathrm{V})$ sites indicated. The probes used and the genomic regions examined are described in Results and Materials and methods. HhaI $(A, D)$ and $H p a I I \mid B, C)$ sites are represented by small vertical lines; transcriptional start sites are shown by arrows in $A$ and $D$. HindIII-digested $\lambda$ DNA size standards are indicated to the left of each blot.

2,31 , whereas the maternally derived allele is hypomethylated at the HhaI sites within the region (lower molecular weight bands, lanes 2,3 ). Within this region lie three CpG sites that become methylated in spermatogenesis and remain methylated exclusively on the paternally derived allele throughout development (Tremblay et al. 1995). This region becomes completely demethylated in Dnmt mutant ES cells (lanes 4,5), indicating a complete loss of methylation at both alleles. In the rescued ES cells $($ lanes 6,8$)$ these sites remained hypomethylated at both alleles, and in vitro differentiation did not result in remethylation of this region (lanes 7,9 ). To see whether remethylation of this region occurred in terminally differentiated cell types in vivo, immortalized fibroblasts prepared from chimeras were examined. Puromycin-selected populations (lanes 11,12), which were derived from the rescued ES cells, displayed no evidence of remethylation at either allele of $H 19$ [compare to fibroblasts derived from a wild-type mouse (lane 10), which display a fully methylated allele (migrating at $3.8 \mathrm{~kb}$ ) and a demethylated allele (lower molecular weight bands)].

Methylation of Igf2r The methylation of the Igf2r gene was determined similarly. It has been shown that an intronic CpG-rich region (Stöger et al. 1993) displays a monoallelic methylation pattern in which the maternally derived allele is completely methylated (migrating at $2.9 \mathrm{~kb}$, Fig. 3B, lane 2) while the paternally derived allele is hypomethylated at the HpaII sites within the region (lower molecular weight bands, lane 2). Both alleles were completely demethylated in Dnmt mutant ES cells (lane 3), indicating a complete loss of methylation 
at both alleles. In the rescued ES cells (lanes 4,5) these sites remained hypomethylated at both alleles. Neither in vitro differentiation of these cells nor 20 serial passages resulted in remethylation of this region /data not shown). The methylation pattern seen in puromycin-selected fibroblasts (lanes 7,8$)$ was similar to that seen in rescued ES cells [compare fibroblasts derived from a wild-type mouse (lane 6), which display a monoallelic methylation pattern, with rescued fibroblasts, which are hypomethylated at both alleles].

Methylation of Igf2 Unlike H19 and Igf2r, Igf2 does not possess a region that becomes differentially methylated in the gametes (Brandeis et al. 1993). However, in adult mice a $1.5-\mathrm{kb}$ region upstream of the first Igf2 promoter has been shown to display a differential methylation pattern (Sasaki et al. 1992; Brandeis et al. 1993; Feil et al. 1994). In contrast to H19 and Igf2r, this region does not display absolute methylation differences, but the paternally derived allele is more methylated, on average. As reported before (Feil et al. 1994), examination of HpaIIdigested genomic DNA from wild-type ES cells revealed a pattern similar to that seen in embryonic and adult tissues, with a fully methylated band (migrating at 1.5 kb, Fig. 3C, lane 2) and a ladder of fragments representing progressive demethylation, moving $3^{\prime}$ to 5 ', of four HpaII sites (lower molecular weight bands, lane 2). This region became mostly demethylated in Dnmt mutant ES cells (lane 4), indicating a near-complete loss of methylation at both alleles. In the rescued ES cells (lanes 6,8), a methylation pattern very similar to wild-type ES cells was established, though the fraction of demethylated 3'-proximal HpaII sites remained higher than in wild-type cells. It is likely that this pattern reflected biallelic methylation. Upon in vitro differentiation, Igf2 became slightly demethylated (lanes 7,9), whereas puromycin-selected fibroblasts (lanes 11,12 ) revealed a state of hypomethylation almost as extensive as that seen in Dnmt mutant ES cells (lanes 4,5), in striking contrast to the pattern seen in wild-type fibroblasts (lane 10).

Expression of H19, Igf2r, and Igf2 Expression was analyzed by RNase protection assay in wild-type, Dnmt mutant, and rescued ES cells before and after induction of differentiation. All undifferentiated cells showed the same level of Igf2r expression and little or no expression of $H 19$ and Igf2 (Fig. 4, B, A, and D, lanes 1, 3, and 5, respectively). Upon differentiation, however, the expression of Igf2 increased significantly in wild-type ES cells (Fig. 4D, lane 2) with little or no increase seen in the mutant (lane 4) or rescued ES cells (lane 6). Although Igf2r expression appeared to increase only slightly upon differentiation of wild-type ES cells (Fig. 4B, lane 2), it showed a noticeable decrease in expression in the differentiated mutant (lane 4) and rescued ES cells (lane 6). Like Igf2, H19 expression increased significantly in wildtype ES cells (Fig. 4A, lane 2) upon differentiation and further increased by at least a factor of two in mutant (lane 4) and rescued ES cells (lane 6). In Dnmt mutant embryos, an increase in $H 19$ expression relative to wild-
A
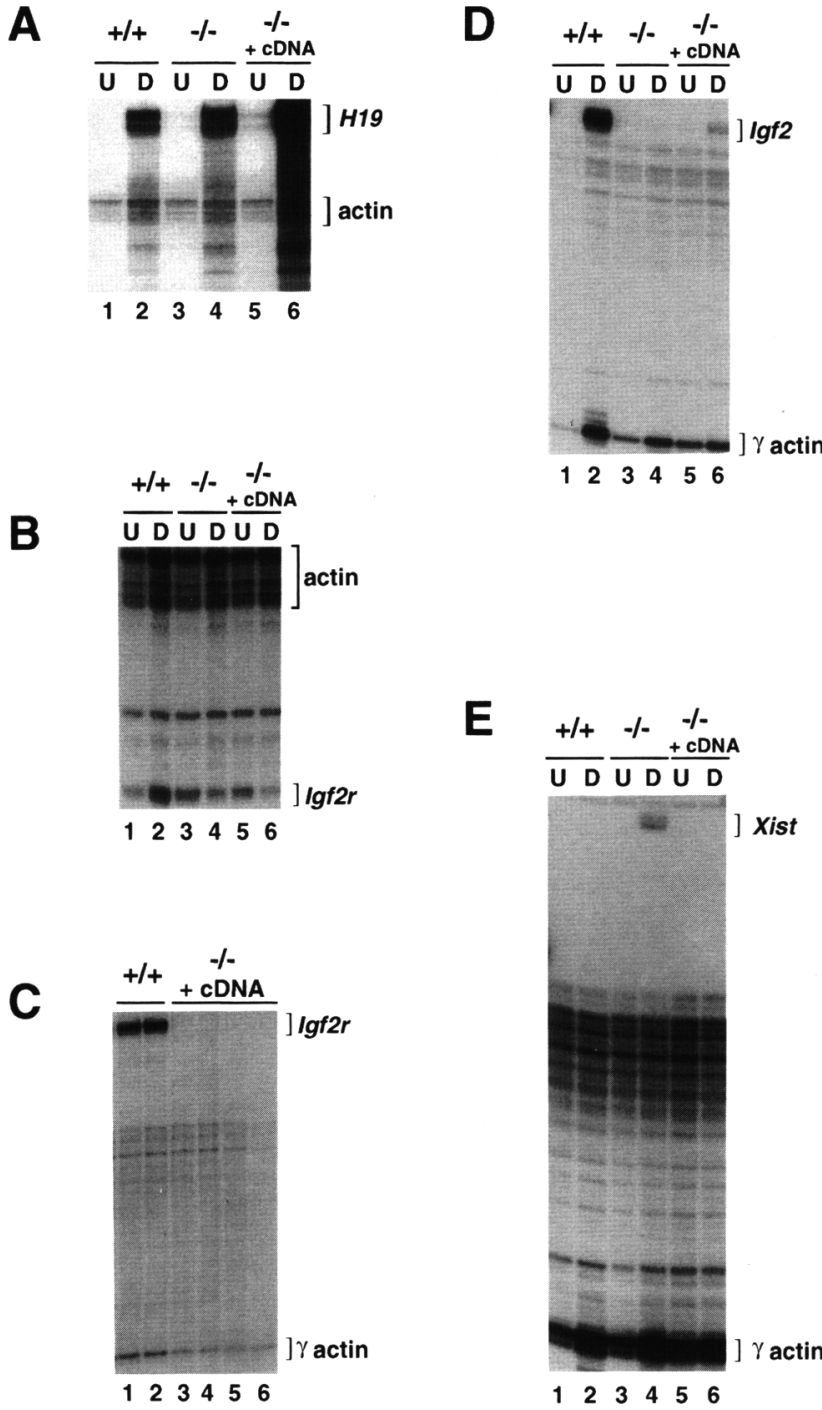

Figure 4. Normal expression of imprinted genes is not restored in rescued ES cells. $(A, B, D, E)$ Total RNA isolated from undifferentiated $|U|$ and in vitro-differentiated (D) ES cells was analyzed by RNase protection using antisense RNA probes for $H 19$ $(A), \operatorname{Igf2r}(B), \operatorname{Igf2}(D)$, and Xist $(E)$. Antisense RNA probes for cytoplasmic actin $(A, B)$ or $\gamma$ actin $(D, E)$ were used as loading controls. Wild-type $\mathrm{J} 1(+1+1$, homozygous Dnmt mutant $1-1$ -1 , and rescued ES cells $(-1-+$ cDNA $)$ are shown. $(C) \operatorname{lgf} 2 r$ RNase protection assay performed on subcloned lines of immortalized fibroblasts prepared from a P7 chimera made between rescued EG cells and a wild-type BALB/c host. (Lanes 1,2) Two wild-type BALB/c lines; (lanes 3-6) four puromycin-resistant lines derived from the injected rescued EG cells. Antisense RNA probes for Igf2 $r$ and $\gamma$ actin (as a loading control) were used.

type embryos has been shown to be caused by biallelic expression of the gene ( $\mathrm{Li}$ et al. 1993). The ES cell lines used for these studies were not marked by any polymorphism to distinguish the alleles of $H 19$, but the overexpression seen in rescued ES cells is consistent with a biallelic transcriptional profile. 
To determine whether expression of these imprinted genes returned to wild-type levels in terminally differentiated cells in vivo, RNA was prepared from wild-type and rescued mutant fibroblasts derived from a P7 $(\mathrm{PO}=$ day of birth) mouse. Igf $2 \mathrm{r}$ expression, which was found at high levels in wild-type fibroblasts (Fig. 4C, lanes 1,21 , was found to be completely extinguished in rescued mutant fibroblasts (lanes 3-6). No significant expression of $H 19$ and Igf 2 was seen in either wild-type or rescued mutant fibroblast clones (data not shown). The lack of expression of $I g f 2$ and H19 in wild-type cells was probably caused by a developmental down-regulation of these genes, for the following reasons: (1) Expression of Igf2 was observed in wild-type fibroblast cultures derived from a 16.5-day-old embryo (data not shown), and (2) H19 is known to be switched off in most tissues soon after birth (Poirier et al. 1991).

Xist This gene, in contrast to the imprinted genes described above, is imprinted only in extraembryonic tissues. The maternal allele is methylated and the paternal allele remains unmethylated throughout cleavage and in the extraembryonic lineage (Ariel et al. 1995; Zuccotti and Monk 1995). Following implantation, however, the maternal imprint is erased and one of two alleles becomes randomly methylated and silent at the time of $\mathrm{X}$ chromosome inactivation (Norris et al. 1994). Xist becomes differentially methylated in a 1.5 -kb region surrounding its promoter (Norris et al. 1994), with two clusters of $\mathrm{CpG}$ sites showing gamete-specific methylationone cluster just upstream of the transcriptional start site (Zuccotti and Monk 1995) and the other 600-bp downstream (Ariel et al. 1995). In male ES cells, with a single, maternally derived $\mathrm{X}$-chromosome, this region was almost completely methylated (Fig. 3D, lane 2). In Dnmt mutant ES cells, this methylation was completely erased (lane 4), including the gamete-specific methylation sites. The same degree of partial methylation seen in wild-type ES cells was observed in the rescued ES cells (lanes 6,8). As shown before (Beard et al. 1995), in vitro differentiation of wild-type 11 cells resulted in an increase in methylation (lane 3), and this was also seen for the rescued ES cells (lanes 7,9). Also as shown previously (Beard et al. 1995), this demethylation resulted in the expression of Xist upon differentiation of Dnmt mutant ES cells (Fig. 4E, lane 4) but not J1 (lane 2) or rescued ES cells (lane 6).

Our results show that methylation and expression of the imprinted genes $H 19$ and $I g f 2 r$ were not restored to normal levels following expression of MTase in homozygous Dnmt mutant ES cells or their differentiated derivatives, in contrast to repetitive DNA sequences and Xist. These observations suggest that once the genomic DNA has been demethylated by deletion of the maintenance MTase, the de novo methylation activity in ES cells can distinguish between two classes of genes: (1) the majority of genes, as evidenced by the repetitive probes in Figure 2 or Xist, which can be remethylated to normal levels so as to assure normal expression patterns during subsequent differentiation; and (2) imprinted genes such as $H 19$ and $I g f 2 r$, which cannot be remethylated and functionally restored once demethylated.

\section{Normal methylation and expression patterns of imprinted genes are restored after passage through the germ line}

To test whether germ-line transmission would restore normal methylation and expression patterns to imprinted genes, five male chimeras, generated from rescued ES cells, were mated to BALB/c females. Three of these chimeras, derived from two independently transfected ES cell lines, produced agouti offspring, indicating contribution of the rescued genome to the germ line. The Dnmt allele that had undergone homologous recombination was transmitted at the expected frequency, and pups carrying the Dnmt cDNA appeared identical to their littermates. Paternal transmission of the imprinted genes contributed by the rescued ES cells makes clear predictions regarding the methylation and expression status of imprinted genes in the offspring. For example, after germ-line transmission the paternal $H 19$ allele should be methylated and the paternal Igf2 allele should be expressed. Consistent with this prediction, the same methylation pattern was seen in pups derived from rescued ES cells (Fig. 5D, lanes 2-4) as in pups derived from the host-blastocyst (lane 1) when H19 methylation in tail preparations was examined as described above. As the examined promoter-proximal region of $H 19$ is known to be unmethylated on the maternally derived allele (Tremblay et al. 1995), we conclude that methylation of the paternally derived allele had occurred during germ-line transmission. Methylation of $I g f 2 r$ and Igf2 was examined in the same regions described above. A wild-type methylation pattern was seen for Igf2r (Fig. $5 F)$, which is consistent with the paternally derived allele of this gene remaining hypomethylated after germline passage. Finally, a wild-type methylation pattern was observed for Igf2 (Fig. 5E), indicating full methylation of the paternally derived allele.

RNase protection analysis was performed on total RNA prepared from gestational day 19.0 embryos. Identical levels of Igf2 RNA were observed in pups derived from the rescued ES cells (Fig. 5B, lane 1) as in pups derived from the host-blastocyst (lane 2). Because Igf2 is not expressed from the maternally derived allele (DeChiara et al. 1991), we conclude that this expression was derived from the paternally transmitted allele. Similar results were observed for expression levels of H19 (Fig. 5A) and Igf2r (Fig. 5C).

These results indicate that normal methylation patterns were restored to both alleles of $H 19$ in the male gonad, resulting in the appropriate expression of both $H 19$ and Igf2 from the paternally derived alleles in the germ-line pups (see Discussion). The presence of an unmethylated Igf $2 r$ allele in these pups, and wild-type levels of $I g f 2 r$ expression in germ-line-transmitted embryos, indicates that this gene was not remethylated in the male gonad. By extension, methylation of both alleles of Igf2r would presumably occur upon germ-line transmis- 
A

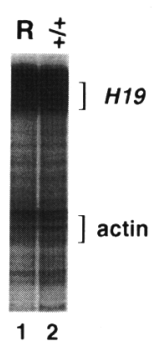

D

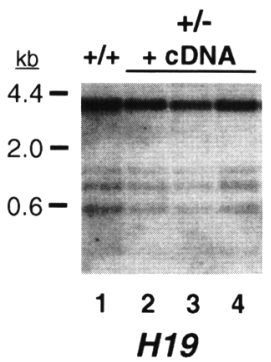

B

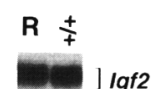

E
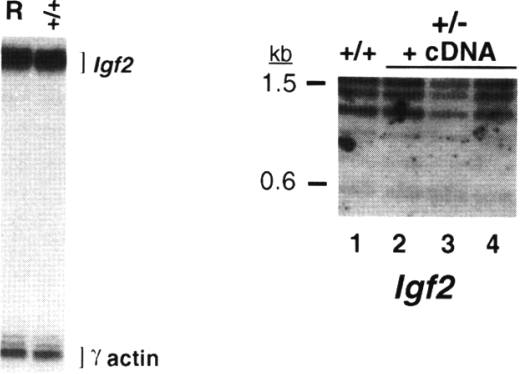

12

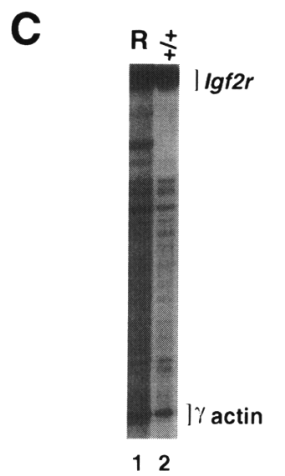

$\mathbf{F}$

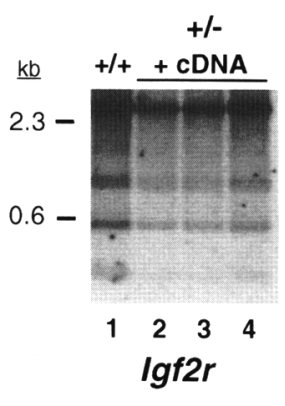

Figure 5. Normal methylation and expression patterns of imprinted genes are restored after passage through the germ line. Southern blot and RNase protection analysis of germ-line embryos and pups produced by a chimera made from rescued ES cells. $(A-C)$ RNase protection analysis performed on whole RNA from embryos, using probes indicated in Fig. 4. A male chimera was mated to BALB/c females, and embryos analyzed at embryonic day 19.0. Black-eyed embryos (R), derived by germ-line transmission of the rescued ES cells, were compared to albino wild-type littermates $1+1+1 .|D-F|$ Southern blot analysis of genomic DNA from postnatal mice. DNA prepared from tails of 3-week old mice was digested with methylationsensitive enzymes and probed with $H 19, \operatorname{Igf2}$, or Igf2r sequences, as described in Fig. $3, A, C$, and $B$, respectively. A wild-type $F_{1}(B A L B / c \times 129 / \mathrm{Sv})$ mouse (lane 1$)$ was compared to three germ-line pups derived from a cross between a chimera generated with rescued ES cells and a BALB/c female (lanes 2-4). HindIII-digested $\lambda$ DNA size standards are indicated to the left of each blot.

sion through a female chimera, but none of the four female chimeras produced agouti offspring. In conclusion, our results suggest that de novo methylation of the im- printed genes $H 19$ and Igf2r, in contrast to "bulk" DNA and the Xist and Igf2 genes, can only occur after passage through the germ line.

\section{Discussion}

The experiments in this study were designed to examine the developmental specificity of DNA methylation activity in the mouse. Because gross genomic hypomethylation is tolerated by Dnmt mutant ES cells, we could start at a specific point in the murine life cycle with a near-complete deficiency of genomic methylation and determine the sites and times of methylation activity. Our results allow the two following conclusions regarding the function of the DNA methyltransferase. (1) Genomic methylation levels in ES cells, which were decreased substantially as a result of the targeted inactivation of the Dnmt gene, could be restored to normal by expression of a functional Dnmt gene. That this remethylation process has restored normal methylation patterns to the genome is inferred by the ability of these remethylated cells to undergo normal differentiation in vitro, to form teratomas, and contribute extensively to chimeras in vivo. In contrast, the parental mutant cells fail to differentiate normally in each of these assays. (2) Upon Dnmt cDNA expression in ES cells, the imprinted genes $H 19$ and Igf2r were not remethylated at either allele and, as a consequence, were not appropriately expressed. Despite this deficiency, the cells were able to contribute substantially to chimeras, including the gonad. Importantly, normal methylation and expression patterns of the two imprinted genes Igf2 and $\mathrm{H} 19$ were restored after passage through the male germ line.

Expression of functional MTase in the fully hypomethylated Dnmt mutant ES cells complemented the mutant phenotype, leading to a substantial restoration of normal genomic DNA methylation levels, as assayed by various repetitive sequence probes. In vitro, the enzyme prefers hemimethylated over unmethylated substrates (Gruenbaum et al. 1982), consistent with the notion that the Dnmt gene encodes the maintenance methyltransferase that is expressed in every cell. How might re-expression of a maintenance methyltransferase activity result in de novo methylation of the unmethylated genomic DNA in mutant ES cells? We have postulated previously that early embryos as well as undifferentiated ES cells express a de novo DNA methyltransferase that is not active in postgastrulation embryos (Jähner et al. 1982) or in differentiated ES cells (Stewart et al. 1982). The low but stable level of genomic DNA methylation in Dnmt mutant ES cells is likely caused by the activity of a separately encoded enzyme (H. Lei, S.P. Oh, R. Jütterman, R. Jaenisch, K.A. Goss, and E. Li, in prep.), which is insufficient to maintain normal methylation levels in the absence of the maintenance DNA methyltransferase. Re-expression of the maintenance methyltransferase would, however, be expected to lead to an increase in methylation levels as it would maintain the methylation levels set by the embryonic de novo methyltransferase activity. 
Dnmt mutant ES cells, while proliferating normally when undifferentiated, grow poorly and die upon induction of differentiation, with the level of genomic DNA methylation decreasing (H. Lei, S.P. Oh, R. Jüttermann, R. Jaenisch, K.A. Goss, and E. Li, in prep.). This is consistent with the embryonic de novo DNA methyltransferase becoming inactive upon differentiation, leading to further hypomethylation. An important issue was whether re-expression of MTase not only would restore genome-wide methylation levels but also lead to rescue of the mutant phenotype, which is a reduction in differentiation capacity in vitro and in vivo / $\mathrm{Li}$ et al. 1992; $\mathrm{H}$. Lei, S.P. Oh, R. Jüttermann, R. Jaenisch, K.A. Goss, and E. Li, in prep.). Remethylated cells have clearly regained the ability to differentiate, as evidenced by three different assays: in vitro differentiation as embryoid bodies, teratoma formation, and contribution to the tissues of chimeras, which represents the most stringent functional test. The extensive coat color contribution to these normal chimeras suggests that single-copy genes had become appropriately remethylated and were correctly expressed, resulting in normal embryonic development. The restoration of wild-type methylation levels and consequent transcriptional inactivation was observed for the single-copy gene Xist. Xist is not imprinted in male ES cells and embryonic derivatives because the single copy of this gene is normally methylated and unexpressed (Norris et al. 1994). The partially methylated pattern seen in normal male ES cells (Beard et al. 1995) was restored to the same degree in rescued ES cells. Importantly, the $\mathrm{CpG}$ sites showing gamete-specific methylation (Ariel et al. 1995; Zuccotti and Monk 1995) were remethylated, supporting the notion that methylation of these sites leads to transcriptional inactivity of Xist. The remethylation of Xist, coupled with the functional complementation assays, suggests that the methylation of all or most other nonimprinted genes is fully restored. It is possible, however, that some genes, whose misexpression would not compromise normal development, are not becoming appropriately remethylated. A detailed study of remethylation at individual loci will address this issue and yield information regarding the functional importance of methylation at specific sites as compared to overall methylation patterns.

The imprinted genes $H 19$ and Igf2r were not remethylated after introduction of the Dnmt cDNA into mutant ES cells. The regions examined for methylation show a gamete-specific methylation difference and are believed to constitute the primary imprinting mark (Barlow 1995). The methylation of these regions and expression status of these genes in rescued ES cells were identical to that seen previously in Dnmt mutant ES cells and embryos (Li et al. 1993). Furthermore, hypomethylation persisted in ES cell-derived fibroblasts isolated from chimeras, and methylation was restored to normal only after germ-line transmission. In contrast to $H 19$ and Igf2r, Igf2 was remethylated extensively in an area that has been shown to be methylated differentially in the adult (Sasaki et al. 1992; Brandeis et al. 1993; Feil et al. 1994) but not in the gametes (Brandeis et al. 1993). Why methylation levels of Igf2 decreased in fibroblasts derived from rescued ES cells is not clear at this time. It has been suggested that Igf 2 expression depends on the availability of two enhancers shared with the closely linked H19 gene, Igf2 being expressed only when the promoter of H19 is methylated and inaccessible to its downstream enhancers (Bartolomei et al. 1993). In mice lacking the H19 gene, a maternally transmitted deletion results in both the methylation and the transcription of Igf2 (Leighton et al. 1995a), whereas in mice lacking the downstream enhancers, a paternally transmitted deletion results in an abrogation of $I g f 2$ transcription from that allele (Leighton et al. 1995b). In this study methylation was restored to $I g f 2$, but little expression of the gene was seen in differentiated ES cells, similar to the Dnmt mutant ES cells and embryos. Our results support the idea that the methylation and expression status of $H 19$ is the primary determinant of $I g f 2$ expression, and that methylation of $I g f 2$ in the region examined does not affect its expression.

Our observations are of general significance in defining the stage in development for, and the mechanisms involved in, the establishment of genomic imprinting. Figure 6 contrasts the developmental changes in methylation of bulk DNA and Xist with that of the imprinted genes $H 19$ and $I g f 2 r$. Although it is generally assumed that imprinted genes acquire their methylation mark during gametogenesis, no direct evidence of an enzyme activity involved in gamete-specific methylation has been demonstrated. Our results show conclusively that passage through the male germ line is necessary to obtain the allele-specific methylation mark on at least one imprinted gene, H19. This suggests the existence of a male-specific de novo methyltransferase activity that may specifically recognize all paternally modified imprinted genes. Presumably a female-specific de novo methyltransferase activity exists, which would be active during oogenesis and would be expected to recognize maternally imprinted genes such as $I g f 2 r$. Although other results strongly suggest that the de novo methyltransferase expressed in ES cells is an independently encoded enzyme (H. Lei, S.P. Oh, R. Jüttermann, R. Jaenisch, K.A. Goss, and E. Li, in prep.), we have no evidence whether the gamete-specific activities are encoded by separate genes, are attributable to modification of the maintenance MTase or the separately encoded de novo methyltransferase activity (H. Lei, S.P. Oh, R. Jüttermann, R. Jaenisch, K.A. Goss, and E. Li, in prep.), or are reflective of a change in chromatin structure affecting substrate accessibility.

It is of interest to compare the rescued mutant ES cells with cells derived from androgenetic (AG) or parthenogenetic (PG) embryos (Fundele and Surani 1994). Chimeras between wild-type embryos and either PG- or AGderived embryonic cells are generally inviable and show highly skewed and complementary distribution of the uniparental cells to different tissues of the chimera (Thomson and Solter 1988; Fundele et al. 1989, 1990; Nagy et al. 1989; Mann et al. 1990). The phenotype of the chimeras has been proposed to be caused by unbalanced 


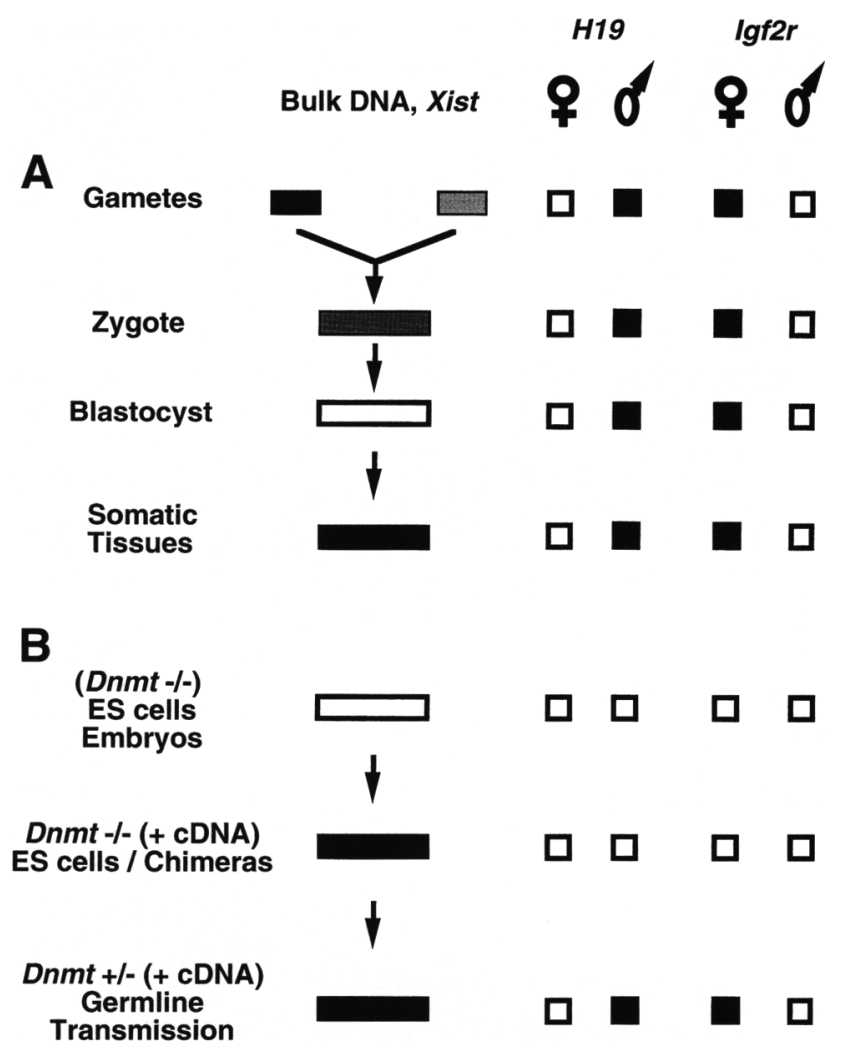

Figure 6. (A) Developmental changes in methylation of bulk DNA and imprinted genes. Bulk DNA and nonimprinted genes undergo consecutive waves of demethylation and de novo methylation in early development before the adult somatic patterns are established (Razin and Shemer 1995). Xist is depicted as nonimprinted as its expression is only imprinted in extraembryonic tissues. The monoallelic methylation patterns of the imprinted genes $H 19$ and Igf2r are established in the male and female gametes, respectively, and are not altered throughout development. $(B)$ Methylation is almost completely erased for all DNA sequences examined in Dnmt mutant ES cells and embryos. Expression of the Dnmt cDNA in mutant ES cells restores the methylation of bulk DNA and single-copy genes such as Xist but does not restore methylation to imprinted genes such as $H 19$ and Igf2r. Methylation of these genes is restored only after transmission through the germ line of male and female chimeras, respectively, implying the presence of gamete-specific DNA methylation processes for imprinted genes. The degree of shading in the boxes indicates the extent of DNA methylation. Maternally and paternally derived alleles are both displayed for $H 19$ and Igf2r.

expression of the imprinted genes in the uniparental component (Allen et al. 1994; Szabo and Mann 1994). In contrast to PG- or AG-derived embryonic cells, the rescued ES cells described here have methylation erased at both paternally and maternally methylated loci, and the subsequent biallelic expression patterns of these genes resulted in a qualitatively different transcriptional profile. Chimeras produced from the rescued ES cells had extensive coat color contribution and were normal. Analysis of organ-specific contribution in chimeras and the possibility of producing embryos derived exclusively from the rescued ES cells (Nagy et al. 1990) will allow us to fully assess the developmental potential of a mouse lacking an imprinted genome.

\section{Materials and methods}

Tissue culture

The wild-type 11 (Li et al. 1992), Dnmt ${ }^{n / n}$ clone 10, (Li et al. 1992), Dnmts $t^{\text {s/s }}$, and $D n m t^{c . c}$ (Li et al. 1993; H. Lei, S.P. Oh, R. Jüttermann, R. Jaenisch, K.A. Goss, and E. Li, in prep.) ES cell lines were used. ES cell lines were cultured as described by Li et al. (1992). ES cells were induced to differentiate into embryoid bodies by suspension culture in bacteriological petri dishes, as described (Robertson 1987), and were collected at day 15 for analysis. A Dnmt ${ }^{s / s}$ EG cell line was derived from a cross between Dnmt $t^{\mathrm{s}+}+$ mice. Primordial germ cells were cultured from gestational day 8.5 embryos on $\mathrm{SI}^{4}-\mathrm{m} 220$ feeder cells with 1000 $\mathrm{U} / \mathrm{ml}$ of LIF and $20 \mathrm{ng} / \mathrm{ml}$ of bFGF, as described (Matsui et al. 19921. The three homozygous mutant ES cell lines and the EG cell line all showed equivalent molecular characteristics and functional capacity before and after transfection of the Dnmt cDNA, and they are collectively referred to as rescued ES cells in the text.

Fibroblasts were prepared by maceration and trypsinization of eviscerated, decapitated embryonic and postnatal carcasses and grown in Dulbecco's modified Eagle medium supplemented with $10 \%$ fetal calf serum, $0.1 \mathrm{~mm}$ nonessential amino acids (GIBCO), $0.1 \mathrm{~mm} \beta$-mercaptoethanol, and antibiotics. SV40 virus infection was as described (Jat et al. 1986). To enrich for fibroblasts derived from the rescued ES cells, puromycin (Sigma) selection $(2 \mu \mathrm{g} / \mathrm{ml})$ was applied after infection. Puromycin-selected populations were plated at $0.5-1.0 \mathrm{cell} /$ well density to produce subcloned lines. Subclones were chosen from those plates with less than one colony per three wells. RNase protection experiments were performed on subcloned fibroblasts prepared from a $\mathrm{P} 7(\mathrm{PO}=$ day of birth) chimera made between a rescued $D n m t^{s \cdot s}$ EG cell line (described above) and a BALB/c host. Methylation data were obtained from these cells, and fibroblasts prepared from two 3-month-old chimeras made with a rescued $D n m t^{s / s}$ ES cell line.

\section{CHIP}

All plasmids were prepared by alkali lysis from bacterial cultures and purified by centrifugation in continuous $\mathrm{CsCl}-\mathrm{ethid}$ ium bromide gradients (Sambrook et al. 1989). pMWT-PURO was made as follows. The Dnmt cDNA was derived from pMG (gift of T. Bestor, Columbia University, New York, NY), which comprises a 4934-bp Dnmt cDNA, starting at an EcoRI site 203 bp upstream of the first ATG and terminating at a BglII site 226 bp downstream of the stop codon TAG. This cDNA was inserted into pPGK-CAS, to utilize the Pgk-1 polyadenylation tract, which comprises the 500-bp PvuII-HindIII fragment at the $3^{\prime}$ end of the Pgk-1 cDNA (Adra et al. 1987). pPGK-CAS is described as the Pgk-1-driven expression vector in van der Lugt et al. (1991). A 4.8-kb Dnmt Nael genomic fragment (Li et al. 1992) was cloned into a unique NaeI site in the open reading frame (ORF) of the Dnmt cDNA, such that the Dnmt cDNA sequence removed upstream of the NaeI site was restored in its genomic context. Finally, a puro ${ }^{R}$ cassette from pPgk-Puro was inserted downstream of the Dnmt cDNA. pPgk-Puro consists of the 660-bp HindIII-ClaI fragment of pBabePuro (Morgenstern and Land 1990) cloned into pPGK-CAS through several intermediate cloning steps.

This construct was designed to act as an insertion vector (Thomas and Capecchi 1987) using a unique HindIII site (Fig. 
1A), which lies $700 \mathrm{bp}$ upstream of the Nael site marking the genomic-cDNA junction and $4.1 \mathrm{~kb}$ downstream of the 5 ' end of the genomic Dnmt fragment. The construct was linearized at this site and then electroporated into ES cells. Upon homologous insertion at the Dnmt locus, the cDNA-genomic hybrid configuration of pMWT-PURO fused the Dnmt promoter and any missing upstream exons to the Dnmt cDNA. Dnmt mRNA transcripts were produced of the same size and amount as the endogenous gene, and they were spliced appropriately to allow production of the full-length protein. For electroporation, $\sim 10^{7}$ ES cells were trypsinized and washed and resuspended in $600 \mu \mathrm{l}$ of electroporation buffer, made as described (Thomas and Capecchi 1987), except with $137 \mathrm{mM} \mathrm{NaCl}$ and $10 \mu \mathrm{g}$ of linearized pMWT-PURO. The cell-DNA mixture was electroporated in a Bio-Rad Gene Pulser at $400 \mathrm{~V}$ and $25 \mu \mathrm{F}$. The cells were plated on $10-\mathrm{cm}$ dishes preplated with $\gamma$-irradiated, puromycinresistant embryonic fibroblasts prepared from pPgk-Puro transgenic mice kind gift of E. Simpson, Jackson Laboratory, Bar Harbor, ME). Media containing $2 \mu \mathrm{g} / \mathrm{ml}$ of puromycin (Sigma) were changed every day, and isolated colonies picked 7-9 days after electroporation. DNA and RNA were analyzed by standard procedures (see below).

\section{Southern blot analysis}

Genomic DNA was prepared from cell cultures and pup tails as described (Laird et al. 1991). Ten micrograms of DNA was digested with 40 units of restriction endonuclease, except for Hhal and HpaII, which were used at double this amount. Digested DNA was electrophoresed in agarose gels, and blotted onto Zetabind nylon membranes (Cuno Laboratory Products). Usual Southern blot procedures were used (Sambrook et al. 1989), with hybridization buffer (Church and Gilbert 1984) and $\left[\alpha-\mathrm{P}^{32}\right] \mathrm{dCTP}$-labeled probe (Feinberg and Vogelstein 1983) prepared as described. Blots were washed at $65^{\circ} \mathrm{C}$ with $0.1 \times \mathrm{SSC} /$ $0.1 \%$ SDS, and exposed to AR-X film (Kodak). The following probes were used: $\mathrm{HV}$ is a 600 -bp HindIII-EcoRV fragment of genomic DNA that includes the first exon of Dnmt; pMO contains a 5.5-kb MoMuLV cDNA fragment (Jähner et al. 1982); pMR150 contains a minor satellite centromeric repeat /Chapman et al. 1984; gift of V. Chapman, Roswell Park Memorial Institute, Buffalo, NY); pBSIISac contains a $3.8-\mathrm{kb}$ genomic SacI fragment from a region of the $H 19$ gene starting 750 bp upstream of the transcriptional start site, identical to the probe used in Tremblay et al. (1995) (generously donated by M. Bartolomei, University of Pennsylvania, Philadelphia); p1269 contains a 720-bp EcoRI-XbaI genomic Igf2 fragment whose 5' end is $\sim 4.5 \mathrm{~kb}$ from the first exon, identical to probe 2 in Feil et al. (1994) (gracious gift of S. Tilghman, Princeton University, NJ); pPP4 contains a 1.1-kb BstBI-MluI genomic Igf2r fragment located within the intronic region 2, identical to the probe used in Stöger et al. (1993) (gift of D. Barlow, IMP, Vienna, Austria); and pXist Mcl contains a $1.5-\mathrm{kb}$ Xist cDNA fragment that includes the transcriptional start site, $1.5 \mathrm{~kb}$ of exon 1 , and the gametespecific methylation sites as reported in Ariel et al. (1995) and Zuccotti and Monk (1995) (provided by H. Willard, Case Western Reserve University, Cleveland, $\mathrm{OH}$ ). A mitochondrial probe was used to assay for completeness of HhaI and HpaII digestions, because the mitochondrial genome does not become methylated. This was a gift of P. Laipis (University of Florida, Gainesville) and comprises bp 4013 to 7720 of the published sequence from mouse $\mathbf{L}$ cells (Bibb et al. 1981).

\section{Northern blot analysis}

RNA was prepared as described (Chomczynski and Sacchi 1987), from confluent ES cell cultures passaged without a fibro- blast feeder layer. Denatured RNA was electrophoresed in formaldehyde-containing agarose gels and blotted onto Zetabind nylon membranes (Cuno) as described (Sambrook et al. 1989). Hybridization, washing, and exposure occurred as described above for DNA analysis. The Dnmt cDNA from pMG was used for a probe, and an $\alpha$-tubulin cDNA probe (pIL $\alpha \mathrm{T} 1)$ (Lemischka et al. 1981 was used to control for loading amounts.

\section{RNase protection assays}

Assays were performed as described for H19, Igf2, and Igf2r (Li et al. 1993), and for Xist (Beard et al. 1995).

\section{Teratoma formation and generation of germ-line chimeras}

Teratomas were produced by preplating $3 \times 10^{6}$ ES cells for 30 min to remove embryonic fibroblasts, resuspending them in 300 $\mu l$ of PBS, and injecting them subcutaneously into the flanks of adult male $129 / \mathrm{Sv}$ mice. Wild-type II, Dnmt $t^{5 / s}$, and rescued $D n m t^{s}$ 'EG and Dnmt c c ES cells were used. Tumors were excised at 3 weeks. Chimeras were made as described (Li et al. 1992), except that two to three ES or EG cells were injected into blastocysts. Male chimeras derived from the two rescued $D n m t^{s}$ ' ES cell lines were mated to BALB/c females, and progeny were analyzed with Southern blot and RNase protection assays.

\section{Acknowledgments}

We thank Klaus Willecke and Edwin Cuppen for pMWT-Puro, Elizabeth Simpson for providing pPgk-Puro transgenic mice, Tim Bestor for pMG, Shirley Tilghman for the H19 and Igf2 probes, Denise Barlow for the Igf2r probes, Marisa Bartolomei for the H19 probe, Huntington Willard for the $5^{\prime}$ Xist probe, Argiris Efstratiadis for the Igf2 probes, Verne Chapman for the centromeric repeat probe, Nathalie van der Lugt for pPGKCAS, Michael Rudnicki for pIL $\alpha$ T1, and Phil Laipis for the mitochondrial DNA probe. L.J.-G. was supported by a Cancer Research Fund of the Damon Runyon-Walter Winchell Foundation Fellowship (DRG-1223). P.W.L. was the recipient of a National Service Research Award (F32 CA 09097) from the National Cancer Institute. E.L. was supported by a grant from Bristol-Myers and Squibb. R.J. was supported by National Institutes of Health grant R35-CA44339.

The publication costs of this article were defrayed in part by payment of page charges. This article must therefore be hereby marked "advertisement" in accordance with 18 USC section 1734 solely to indicate this fact.

\section{References}

Adra, C.N., P.H. Boer, and M.W. McBurney. 1987. Cloning and expression of the mouse $p g k-1$ gene and the nucleotide sequence of its promoter. Gene 60: 65-74.

Allen, N.D., S.C. Barton, K. Hilton, M.L. Norris, and M.A. Surani. 1994. A functional analysis of imprinting in parthenogenetic embryonic stem cells. Development 120: 14731482 .

Ariel, M., E. Robinson, J.R. McCarrey, and H. Cedar. 1995. Gamete-specific methylation correlates with imprinting of the murine Xist gene. Nature Genet. 9: 312-315.

Barlow, D.P. 1995. Gametic imprinting in mammals. Science 270: 1610-1613.

Barlow, D.P., R. Stöger, B.G. Herrmann, K. Saito, and N. Schweifer. 1991. The mouse insulin-like growth factor 
type- 2 receptor is imprinted and closely linked to the Tme locus. Nature 349: 84-87.

Bartolomei, M.S., S. Zemel, and S.M. Tilghman. 1991. Parental imprinting of the mouse $H 19$ gene. Nature 351: 153-155.

Bartolomei, M.S., A.L. Webber, M.E. Brunkow, and S.M. Tilghman. 1993. Epigenetic mechanisms underlying the imprinting of the mouse $H 19$ gene. Genes \& Dev. 7: 1663-1673.

Beard, C., E. Li, and R. Jaenisch. 1995. Loss of methylation activates $X i s t$ in somatic but not in embryonic cells. Genes \& Dev. 9: 2325-2334.

Bestor, T.H. and V.M. Ingram. 1983. Two DNA methyltransferases from murine erythroleukemia cells: Purification, sequence specificity, and mode of interaction with DNA. Proc. Natl. Acad. Sci. 80: 5559-5563.

Bibb, M.J., R.A. Van Etten, C.T. Wright, M.W. Walberg, and D.A. Clayton. 1981. Sequence and gene organization of mouse mitochondrial DNA. Cell 26: 167-180.

Brandeis, M., T. Kafri, M. Ariel, J.R. Chaillet, J. McCarrey, A. Razin, and H. Cedar. 1993. The ontogeny of allele-specific methylation associated with imprinted genes in the mouse. EMBO /. 12: 3669-3677.

Chaillet, J.R., T.F. Vogt, D.R. Beier, and P. Leder. 1991. Parentalspecific methylation of an imprinted transgene is established during gametogenesis and progressively changes during embryogenesis. Cell 66: 77-83.

Chapman, V., L. Forrester, J. Sanford, N. Hastie, and J. Rossant. 1984. Cell lineage-specific undermethylation of mouse repetitive DNA. Nature 307: 284-286.

Chomczynski, P. and N. Sacchi. 1987. Single-step method of RNA isolation by acid guanidinium thiocyanate-phenolchloroform extraction. Anal. Biochem. 162: 156-159.

Church, G. and W. Gilbert. 1984. Genomic sequencing. Proc. Natl. Acad. Sci. 81: 1991-1995.

DeChiara, T.M., E.J. Robertson, and A. Efstratiadis. 1991. Parental imprinting of the mouse insulin-like growth factor II gene. Cell 64: 849-859.

Feil, R., J. Walter, N.D. Allen, and W. Reik. 1994. Developmental control of allelic methyation in the imprinted mouse Igf2 and $H 19$ genes. Development 120: 2933-2943.

Feinberg, A.P. and B. Vogelstein. 1983. A technique for radiolabeling DNA restriction endonuclease fragments to high specific activity. Anal. Biochem. 132: 6-13.

Fundele, R.H. and M.A. Surani. 1994. Experimental embryological analysis of genetic imprinting in mouse development Dev. Genet. 15: 515-522.

Fundele, R., M.L. Norris, S.C. Barton, W. Reik, and M.A. Surani. 1989. Systematic elimination of parthenogenetic cells in mouse chimeras. Development 106: 29-35.

Fundele, R.H., M.L. Norris, S.C. Barton, M. Fehlau, S.K. Howlett, W.E. Mills, and M.A. Surani. 1990. Temporal and spatial selection against parthenogenetic cells during development of fetal chimeras. Development 108: 203-211.

Giddings, S.J., C.D. King, K.W. Harman, J.F. Flood, and L.R. Carnaghi. 1994. Allele specific inactivation of insulin 1 and 2 , in the mouse yolk sac, indicates imprinting. Nature Genet. 6: 310-313.

Gruenbaum, Y., H. Cedar, and A. Razin. 1982. Substrate and sequence specificity of a eukaryotic DNA methylase. Nature 295: 620-622.

Guillemot, F., T. Caspary, S.M. Tilghman, N.G. Copeland, D.J. Gilbert, N.A. Jenkins, D.J. Anderson, A.L. Joyner, J. Rossant, and A. Nagy. 1995. Genomic imprinting of Mash2, a mouse gene required for trophoblast development. Nature Genet. 9: $235-242$.

Hatada, I. and T. Mukai. 1995. Genomic imprinting of $p 57^{\text {KIP2 }}$ a cyclin-dependent kinase inhibitor, in mouse. Nature
Genet. 11: 204-206

Hayashizaki, Y., H. Shibata, S. Hirotsune, H. Sugino, Y. Okazaki, N. Sasaki, K. Hirose, H. Imoto, H. Okuizumi, M. Muramatsu, H. Komatsubara, T. Shiroishi, K. Moriwaki, M. Katsuki, N. Hatano, H. Sasaki, T. Ueda, N. Mise, N. Takagi, C. Plass, and V.M. Chapman. 1994. Identification of an imprinted U2af binding protein related sequence on mouse chromosome 11 using the RLGS method. Nature Genet. 6: $33-40$.

Jähner, D., H. Stuhlmann, C.L. Stewart, K. Harbers, J. Löhler, I. Simon, and R. Jaenisch. 1982. De novo methylation and expression of retroviral genomes during mouse embryogenesis. Nature 298: 623-628.

Jat, P.S., C.L. Cepko, R.C. Mulligan, and P.A. Sharp. 1986. Recombinant retroviruses encoding simian virus 40 large $T$ antigen and polyomavirus large and middle $\mathrm{T}$ antigens. Mol. Cell. Biol. 6: 1204-1217.

Kafri, T., M. Ariel, M. Brandeis, R. Shemer, L. Urven, J. McCarrey, H. Cedar, and A. Razin. 1992. Developmental pattern of gene-specific DNA methylation in the mouse embryo and germ line. Genes \& Dev. 6: 705-714.

Kaneko-Ishino, T., Y. Kuroiwa, N. Miyoshi, T. Kohda, R. Suzuki, M. Yokoyama, S. Viville, S.C. Barton, F. Ishino, and M.A. Surani. 1995. Peg1/Mest imprinted gene on chromosome 6 identified by cDNA subtraction hybridization. $\mathrm{Na}$ ture Genet. 11: 52-59.

Kay, G.F., G.D. Penny, D. Patel, A. Ashworth, N. Brockdorff, and S. Rastan. 1993. Expression of Xist during mouse development suggests a role in the initiation of $\mathrm{X}$ chromosome inactivation. Cell 72: 171-182.

Laird, P.W., A. Zijderveld, K. Linders, M.A. Rudnicki, R. Jaenisch, and A. Berns. 1991. Simplified mammalian DNA isolation procedure. Nucleic Acids Res. 19: 4293

Leff, S.E., C.I. Brannan, M.L. Reed, T. Özçelik, U. Francke, N.G. Copeland, and N.A. Jenkins. 1992. Maternal imprinting of the mouse Snrpn gene and conserved linkage homology with the human Prader-Willi syndrome region. Nature Genet. 2: $259-264$

Leighton, P.A., R.S. Ingram, J. Eggenschwiler, A. Efstratiadis, and S.M. Tilghman. 1995a. Disruption of imprinting caused by deletion of the $H 19$ gene region in mice. Nature 375: 34 39.

Leighton, P.A., J.R. Saam, R.S. Ingram, C.L. Stewart, and S.M. Tilghman. 1995b. An enhancer deletion affects both $H 19$ and Igf2 expression. Genes \& Dev. 9: 2079-2089.

Lemischka, I.R., S. Farmer, V.R. Racaniello, and P.A. Sharp. 1981. Nucleotide sequence and evolution of a mammalian $\alpha$-tubulin messenger RNA. I. Mol. Biol. 151: 101-120.

Li, E., T.H. Bestor, and R. Jaenisch. 1992. Targeted mutation of the DNA methyltransferase gene results in embryonic lethality. Cell 69: 915-926.

Li, E., C. Beard, and R. Jaenisch. 1993. Role for DNA methylation in genomic imprinting. Nature 366: 362-365.

Mann, J.R., I. Gadi, M.L. Harbison, S.J. Abbondanzo, and C.L. Stewart. 1990. Androgenetic mouse embryonic stem cells are pluripotent and cause skeletal defects in chimeras: Implications for genetic imprinting. Cell 62: 251-260.

Matsui, Y., K. Zsebo, and B.L.M. Hogan. 1992. Derivation of pluripotential embryonic stem cells from murine primordial germ cells in culture. Cell 70: 841-847.

Monk, M., M. Boubelik, and S. Lehnert. 1987. Temporal and regional changes in DNA methylation in the embryonic, extraembryonic and germ cell lineages during mouse embryo development. Development 99: 371-382.

Morgenstern, J.P. and H. Land. 1990. Advanced mammalian gene transfer: High titre retroviral vectors with multiple 
drug selection markers and a complementary helper-free packaging cell line. Nucleic Acids Res. 18: 3587-3596.

Nagy, A., M. Sass, and M. Markkula. 1989. Systematic nonuniform distribution of parthenogenetic cells in adult mouse chimaeras. Development 106: 321-324.

Nagy, A., E. Gócza, E. Merentes Dias, V.R. Prideaux, E. Iványi, M. Markkula, and J. Rossant. 1990. Embryonic stem cells alone are able to support fetal development in the mouse. Development 110: 815-821.

Norris, D.P., D. Patel, G.F. Kay, G.D. Penny, N. Brockdorff, S.A. Sheardown, and S. Rastan. 1994. Evidence that random and imprinted Xist expression is controlled by preemptive methylation. Cell 77: 41-51.

Poirier, F., C.-T.J. Chan, P.M. Timmons, E.J. Robertson, M.J. Evans, and P.W.J. Rigby. 1991 . The murine $H 19$ gene is activated during embryonic stem cell differentiation in vitro and at the time of implantation in the developing embryo. Development 113: 1105-1114.

Razin, A. and R. Shemer. 1995. DNA methylation in early development. Hum. Mol. Genet. 4: 1751-1755.

Reik, W., A. Collick, M.L. Norris, S.C. Barton, and M.A. Surani. 1987. Genomic imprinting determines methylation of parental alleles in transgenic mice. Nature 328: 248-25l.

Robertson, E.J. 1987. Embryo-derived stem cell lines. In Teratocarcinomas and embryonic stem cells: A practical approach (ed. E.J. Robertson), pp. 71-112. IRL Press, Oxford, UK.

Rouleau, J., G. Tanigawa, and M. Szyf. 1992. The mouse DNA methyltransferase 5 '-region. A unique housekeeping gene promoter. I. Biol. Chem. 267: 7368-7377.

Sambrook, J., E. Fritsch, and T. Maniatis. 1989. Molecular clon. ing: A laboratory manual. Cold Spring Harbor Laboratory Press, Cold Spring Harbor, N.Y.

Sapienza, C., A.C. Peterson, J. Rossant, and R. Balling. 1987. Degree of methylation of transgenes is dependent on gamete of origin. Nature 328: 251-254.

Sasaki, H., P.A. Jones, J.R. Chaillet, A.C. Ferguson-Smith, S.C. Barton, W. Reik, and M.A. Surani. 1992. Parental imprinting: Potentially active chromatin of the repressed maternal allele of the mouse insulin-like growth factor II (Igf2) gene. Genes \& Dev. 6: 1843-1856.

Stewart, C.L., H. Stuhlmann, D. Jahner, and R. Jaenisch. 1982. De novo methylation, expression, and infectivity of retroviral genomes introduced into embryonal carcinoma cells. Proc. Natl. Acad. Sci. 79: 4098-4102.

Stöger, R., P. Kubicka, C.-G. Liu, T. Kafri, A. Razin, H. Cedar, and D.P. Barlow. 1993. Maternal-specific methylation of the imprinted mouse Igf $2 r$ locus identifies the expressed locus as carrying the imprinting signal. Cell 73: 61-71.

Stuhlmann, H., D. Jähner, and R. Jaenisch. 1981. Infectivity and methylation of retroviral genomes is correlated with expression in the animal. Cell 26: 221-232.

Surani, M.A. 1994. Genomic imprinting: Control of gene expression by epigenetic inheritance. Curr. Opin. Cell Biol. 6: 390-395.

Swain, J.L., T.A. Stewart, and P. Leder. 1987. Parental legacy determines methylation and expression of an autosomal transgene: A molecular mechanism for parental imprinting. Cell 50: 719-727.

Szabo, P. and J.R. Mann. 1994. Expression and methylation of imprinted genes during in vitro differentiation of mouse parthenogenetic and androgenetic embryonic stem cell lines. Development 120: 1651-1660.

1995. Biallelic expression of imprinted genes in the mouse germ line: Implications for erasure, establishment, and mechanisms of genomic imprinting. Genes \& Dev.
9: $1857-1868$.

Thomas, K.R. and M.R. Capecchi. 1987. Site-directed mutagenesis by gene targeting in mouse embryo-derived stem cells. Cell 51: 503-512.

Thomson, J.A. and D. Solter. 1988. The developmental fate of androgenetic, parthenogenetic, and gynogenetic cells in chimeric gastrulating mouse embryos. Genes \& Dev. 2: 1344 1351.

Tremblay, K.D., J.R. Saam, R.S. Ingram, S.M. Tilghman, and M.S. Bartolomei. 1995. A paternal-specific methylation imprint marks the alleles of the mouse $H 19$ gene. Nature Genet. 9: 407-413.

van der Lugt, N., E.R. Maandag, H. te Riele, P.W. Laird, and A. Berns. 1991. A pgk::hprt fusion as a selectable marker for targeting of genes in mouse embryonic stem cells: disruption of the T-cell receptor $\delta$-chain-encoding gene. Gene 105: 263-267.

Villar, A.J. and R.A. Pedersen. 1994. Parental imprinting of the Mas protooncogene in mouse. Nature Genet. 8: 373-379.

Wevrick, R., J.A. Kerns, and U. Francke. 1994. Identification of a novel paternally expressed gene in the Prader-Willi syndrome region. Hum. Mol. Genet. 3: 1877-1882.

Yeivin, A. and A. Razin. 1993. Gene methylation patterns and expression. In DNA methylation: Molecular biology and biological significance (ed. J.P. Jost and H.P. Saluz), pp. 523568. Birkhäuser Verlag, Basel, Switzerland.

Zuccotti, M. and M. Monk. 1995. Methylation of the mouse $X i s t$ gene in sperm and eggs correlates with imprinted Xist expression and paternal X-inactivation. Nature Genet. 9: $316-320$. 


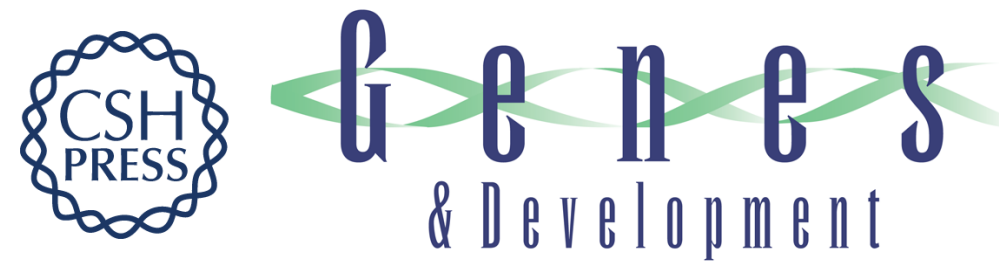

\section{Germ-line passage is required for establishment of methylation and expression patterns of imprinted but not of nonimprinted genes.}

K L Tucker, C Beard, J Dausmann, et al.

Genes Dev. 1996, 10:

Access the most recent version at doi:10.1101/gad.10.8.1008

References This article cites 65 articles, 22 of which can be accessed free at:

http://genesdev.cshlp.org/content/10/8/1008.full.html\#ref-list-1

License

Email Alerting

Service

Receive free email alerts when new articles cite this article - sign up in the box at the top right corner of the article or click here.

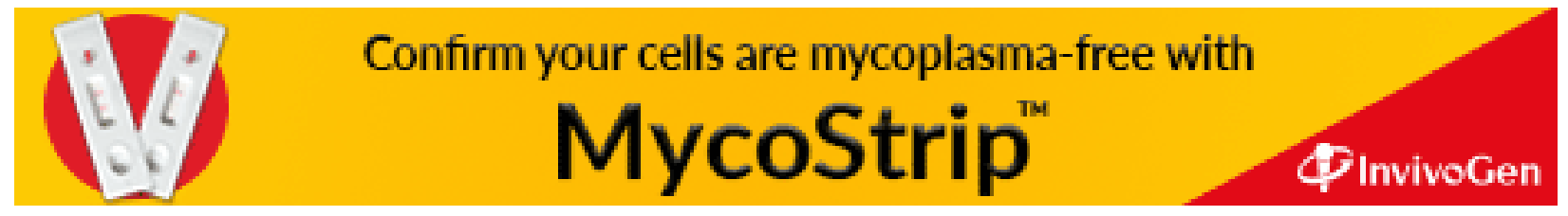

